Regular Article

pISSN: 2288-9744, eISSN: 2288-9752

Journal of Forest and Environmental Science

Vol. 30, No. 2, pp. 201-207, May, 2014

http://dx.doi.org/10.7747/JFS.2014.30.2.201

\title{
Nonlinear Height-DBH Growth Models for Larix kaempferi in Gangwon and North Gyeongsang Province
}

\author{
Daesung Lee ${ }^{1}$, Jungkee Choi ${ }^{1, *}$, Yeongwan $\mathrm{Seo}^{2}$ and Euigyeong $\mathrm{Kim}^{3}$ \\ ${ }^{1}$ Department of Forest Management, College of Forest and Envirommental Sciences, Kangrwon National University, Chuncheon 200-701, Republic of \\ Korea \\ ${ }^{2}$ Institute of Forest Science, Kangrwon National University, Chuncheon 200-701, Republic of Korea \\ ${ }^{3}$ Department of Forest Environmental Resources, College of Agriculture and Life Science, Gyeongsang National University, Jimju 600-701, Republic \\ of Korea
}

\begin{abstract}
This study was conducted to estimate the best-fit nonlinear height-DBH growth models for Larix kaempferi in Gangwon and North Gyeongsang province in South Korea. Exponential, Modified Logistic, Chapman-Richards, and Weibull function were used for estimating height-DBH models. To evaluate the selected models, $\mathrm{R}^{2}, \mathrm{RMSE}, \mathrm{MD}, \mathrm{MAD}$, and residual plots were performed in each model. Also, the coefficients and patterns in models of the previous studies were compared with those in this study. The result showed that Weibull equation was found to be the best-fit model with $R^{2}=0.9837$, $\mathrm{RMSE}=2.6133, \mathrm{MD}=0.0089$, and $\mathrm{MAD}=2.0896$. All model parameters in our study had similar values to those in the previous models except for asymptotic parameter a. Our research result showed that Gangwon and North Gyeongsang province were superior to other provinces with regard to height growth for Larix kaempferi.
\end{abstract}

Key Words: Nonlinear growth models, Exponential, Modified Logistic, Chapman-Richards, Weibull

\section{Introduction}

Larix kaempferi has been planted in 700 thousand ha across South Korea since 1960s, and has become widely known as the representative of the rapid growing trees. In the present Larix kaempferi plantation accounts for $16.5 \%$ (425 thousand ha) out of the total coniferous forest area in South Korea (Korea Forest Service 2012). This is the largest area among the nations' main coniferous plantation. In addition, about $380,000 \mathrm{~m}^{3}$ of the timber is annually produced and mostly used for sawlog, plywood and wood chip
(Korea Forest Research Institute 2012). At present Larix kaempferi is one of the main commercial tree species in the temperate climate region of South Korea.

Forest resource inventory should be involved to understand tree growth and stand structure. DBH and height are an essential part of independent variables in growth and yield models, and thus these measurements must be entailed. Compared with measuring DBH, however, measuring height takes much more time and efforts. Therefore, it is common that tree height is estimated from $\mathrm{DBH}$ by developing height-DBH growth model (Avery and Burkhart

Received: May 6, 2014. Revised: May 10, 2014. Accepted: May 11, 2014.

Corresponding author: Jungkee Choi

Department of Forest Management, College of Forest and Environmental Sciences, Kangwon National University, Chuncheon 200-701, Republic of Korea

Tel: 82-33-250-8337, Fax: 82-33-259-5617, E-mail: jungkee@kangwon.ac.kr 
2002).

A number of height-DBH equations have already been developed all over the world, and the practical functions were utilized for regional main species in many developed countries (Huang et al. 1992; Hökkä 1997; Soares and Tomé 2002; Dorado et al. 2006; Sánchez-González et al. 2007). In Korea, the height-DBH functions have also been studied for the major species (Lee 1996; Kwak et al. 2004;
Lee et al. 2009; Lumbres et al. 2011; Seo et al. 2011). However, it is still insufficient in the height-DBH models for Larix kaempferi, especially for the regional growth estimation. Therefore, the objectives of this research are to estimate the best-fit nonlinear height-DBH models for Larix kaempferi, to evaluate the models using test statistics, and to compare our models with the previous studies.

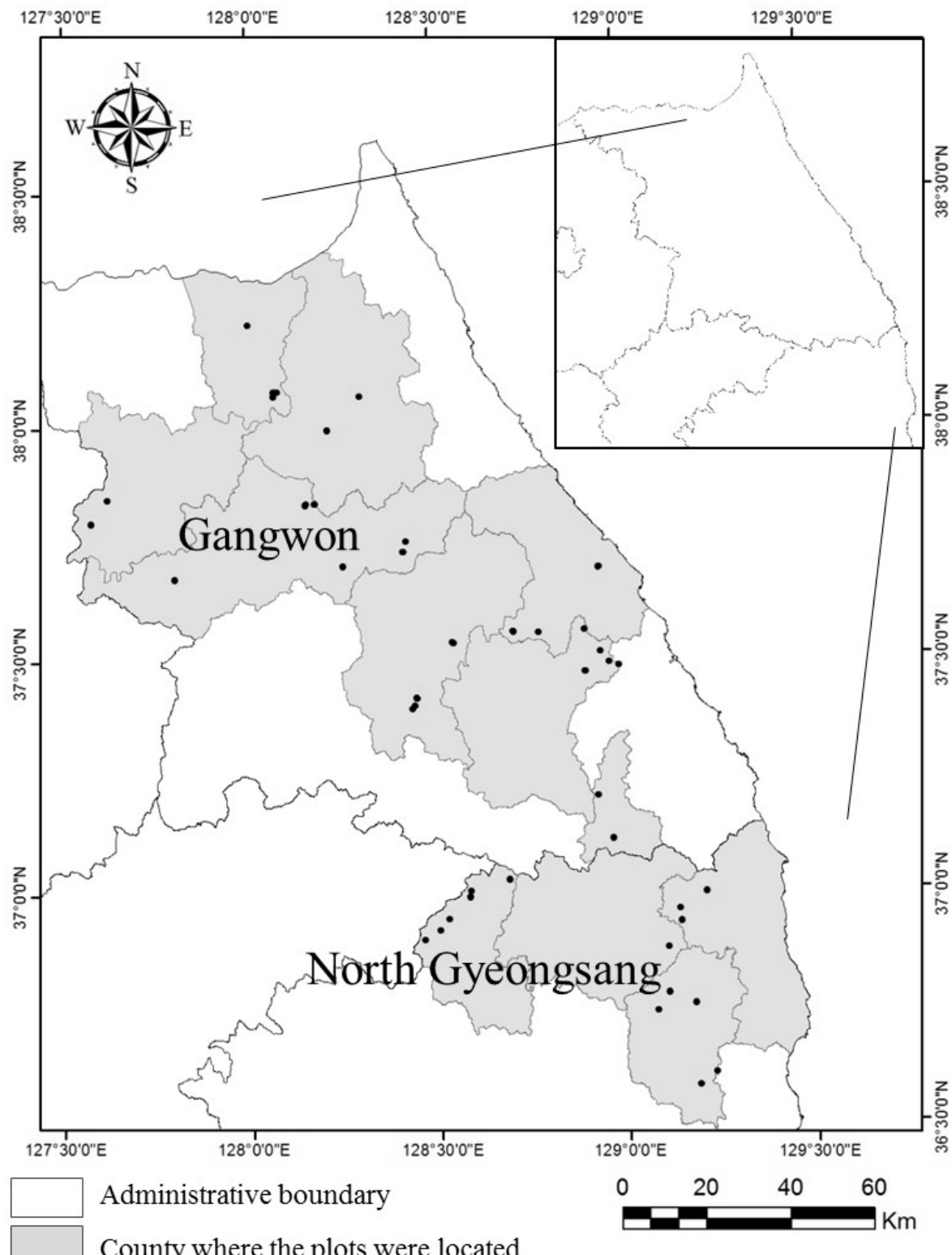

- Permanent plot

Fig. 1. Study area for height-DBH growth models of Larix kaempferi. 


\section{Materials and Methods}

\section{Data}

The data was collected from the plots of Larch plantations, which are widely located from Gangwon to North Gyeongsang province (Fig. 1). The plots were established in unthinned stands for the thinning study (Lee and Choi 2014). Three plots were installed in each region on the basis of plot sizes and thinning intensity: $20 \mathrm{~m} \mathrm{x} 20 \mathrm{~m}$ for unthinned plots, $25 \mathrm{~m}$ x $25 \mathrm{~m}$ for light thinned plots, and $30 \mathrm{~m}$ x $30 \mathrm{~m}$ for heavy thinned plots. Finally, it consisted of 135 plots (45 regions $\mathrm{x} 3$ plots) to monitor individual tree and stand growth.

Diameter at Breast Height (DBH) of an individual tree was measured at $1.2 \mathrm{~m}$ above the ground by diameter tape, and tree height was measured by Vertex IV. Both DBH and tree height were recorded on the first decimal for a total of 3,825 Larch trees. DBH ranged from $6.2 \mathrm{~cm}$ to $57.6 \mathrm{~cm}$, and tree height ranged from $3.5 \mathrm{~m}$ to $34.0 \mathrm{~m}$. The statistics of the dataset were shown in Table 1.

\section{Model selection and validation}

In this study, four nonlinear height-DBH growth mod-

Table 1. Summary statistics of Larix kaempferi inventory data $(\mathrm{n}=3825)$

\begin{tabular}{lccc}
\hline & Age & DBH $(\mathrm{cm})$ & Height $(\mathrm{m})$ \\
\hline Mean & 35 & 22.2 & 19.8 \\
Maximum & 60 & 57.6 & 34.0 \\
Minimum & 19 & 6.2 & 3.5 \\
SD & 12 & 7.5 & 5.3 \\
\hline
\end{tabular}

els were used for Larix kaempferi; Exponential, Modified Logistic, Chapman-Richards, and Weibull (Table 2). The fitting of models was accomplished using the PROC NLIN procedure on SAS 9.3 software (SAS Institute Inc. 2011). After estimating the parameters for each model, the shape of curves and coefficients were compared with those from the previous studies (Lumbres et al. 2011; Seo et al. 2011).

In the process of model validation, four fit statistics were carried out and compared to determine the best-fit model. Coefficient of determination $\left(\mathrm{R}^{2}\right)$ was typically used to provide all the functions with power of explanation about regression lines. Additionally, root mean square error (RMSE), mean deviation (MD), and mean absolute deviation (MAD) were examined. Also, residual plots were displayed to verify the homoscedasticity of each model. The equations were summarized as follows:

$$
R^{2}=1-\left[\sum_{i=1}^{n}\left(H_{i}-\widehat{H}_{i}\right)^{2} / \sum_{i=1}^{n}\left(H_{i}-\bar{H}\right)^{2}\right]
$$

$$
\begin{aligned}
\text { RMSE } & =\sqrt{\sum_{i=1}^{n}\left(H_{i}-\widehat{H}_{i}\right)^{2} / n} \\
\mathrm{MD} & =\sum_{i=1}^{n}\left(H_{i}-\widehat{H}_{i}\right) / n \\
\mathrm{MAD} & =\sum_{i=1}^{n}\left|H_{i}-\widehat{H}_{i}\right| / n
\end{aligned}
$$

Table 2. Selected nonlinear height-DBH growth models for Larix kaempferi

\begin{tabular}{clll}
\hline & Model name & \multicolumn{1}{c}{ Equations } & \multicolumn{1}{c}{ References } \\
\hline$[1]$ & Exponential & $H T=1.2+a \times e^{\frac{b}{(D B H+c)}}$ & Ratkowsky 1990 \\
{$[2]$} & Modified Logistic & $H T=1.2+\frac{a}{1+b^{-1} \times D B H^{c}}$ & Ratkowsky and Reedy 1986; Huang et al. 1992 \\
{$[3]$} & Chapman-Richards & $H T=1.2+a\left(1-e^{-b D B H}\right)^{c}$ & Richards 1959; Chapman 1961 \\
{$[4]$} & Weibull & $H T=1.2+a\left(1-e^{-b D B H^{c}}\right)$ & Yang et al. 1978 \\
\hline
\end{tabular}

Note: HT is the tree total height $(\mathrm{m}) ; \mathrm{DBH}$ is the tree diameter at breast height $(\mathrm{cm}) ; 1.2(\mathrm{~m})$ is the distance from the ground to the point where $\mathrm{DBH}$ was measured; a, b, c are the parameters to be estimated in this study; $e$ is the base of natural logarithm. 


$$
\text { Residual }=H_{i}-\widehat{H}_{i}
$$

Where $H_{i}=$ measured height for the ith tree, $\hat{H}_{i}=$ predicted height for the $i$ th tree, $\bar{H}=$ measured mean tree height, $\mathrm{n}=$ the total number of observations used to fit the model.

\section{Results and Discussion}

\section{Model development}

The parameters and fit statistics for each height-DBH growth model were shown in Table 3. All the models used for height-diameter curves were found to be significant at the $5 \%$ level. The form of all equations was an asymptotic curve, which converges an asymptote (Fig. 2). A subtle difference was found in the range of $\mathrm{DBH}<10 \mathrm{~cm}$ or $\mathrm{DB}$ $\mathrm{H}>40 \mathrm{~cm}$, although the shape of model curves were anal- ogous in the dense sample range.

In comparison with parameters of Lumbres et al. (2011) and Seo et al. (2011) using Larch data in Korea, parameter $\mathrm{b}$ in all models was similar with small difference ranged from 0.0009 to 8.6107 , and parameter $\mathrm{c}$ was also similar with small difference ranged from 0.1165 to 4.1236 . However, parameter a, which represents an asymptotic, was higher than that of the previous models resulting in higher height over DBH than other studies. Overall, the abnormal parameters were not found.

\section{Model validation}

Each fit statistics of the models had similar values; $\mathrm{R}^{2}$ ranged in 0.9836-0.9837, RMSE in 2.6133-2.6204, MD in 0.0001-0.0108, and MAD in 2.0896-2.0975. When all criteria were considered, Weibull function was verified as the best-fit model; $\mathrm{R}^{2}=0.9837$, $\mathrm{RMSE}=2.6133, \mathrm{MD}=$

Table 3. Coefficient and fit statistics of four selected models for Larix kaempferi

\begin{tabular}{|c|c|c|c|c|c|c|c|c|c|}
\hline & \multirow{2}{*}{ Model name } & \multicolumn{3}{|c|}{ Parameter } & \multicolumn{5}{|c|}{ Fit statistics } \\
\hline & & $\mathrm{a}$ & $\mathrm{b}$ & c & $\mathrm{R}^{2}$ & RMSE & $\mathrm{MD}$ & MAD & $\operatorname{Pr}>F$ \\
\hline$[1]$ & Exponential & 41.3853 & -17.6356 & 1.1545 & 0.9836 & 2.6204 & 0.0017 & 2.0975 & $<0.0001$ \\
\hline$[2]$ & Modified Logistic & 33.6484 & 0.0061 & 1.7512 & 0.9837 & 2.6144 & 0.0001 & 2.0910 & $<0.0001$ \\
\hline$[3]$ & Chapman-Richards & 29.7842 & 0.0707 & 1.8157 & 0.9837 & 2.6135 & 0.0108 & 2.0900 & $<0.0001$ \\
\hline$[4]$ & Weibull & 28.6591 & 0.0139 & 1.4215 & 0.9837 & 2.6133 & 0.0089 & 2.0896 & $<0.0001$ \\
\hline
\end{tabular}

Note: $\mathrm{R}^{2}$ is the coefficient of determination; RMSE is the root mean square error; MD is the mean deviation; MAD is the mean absolute deviation.

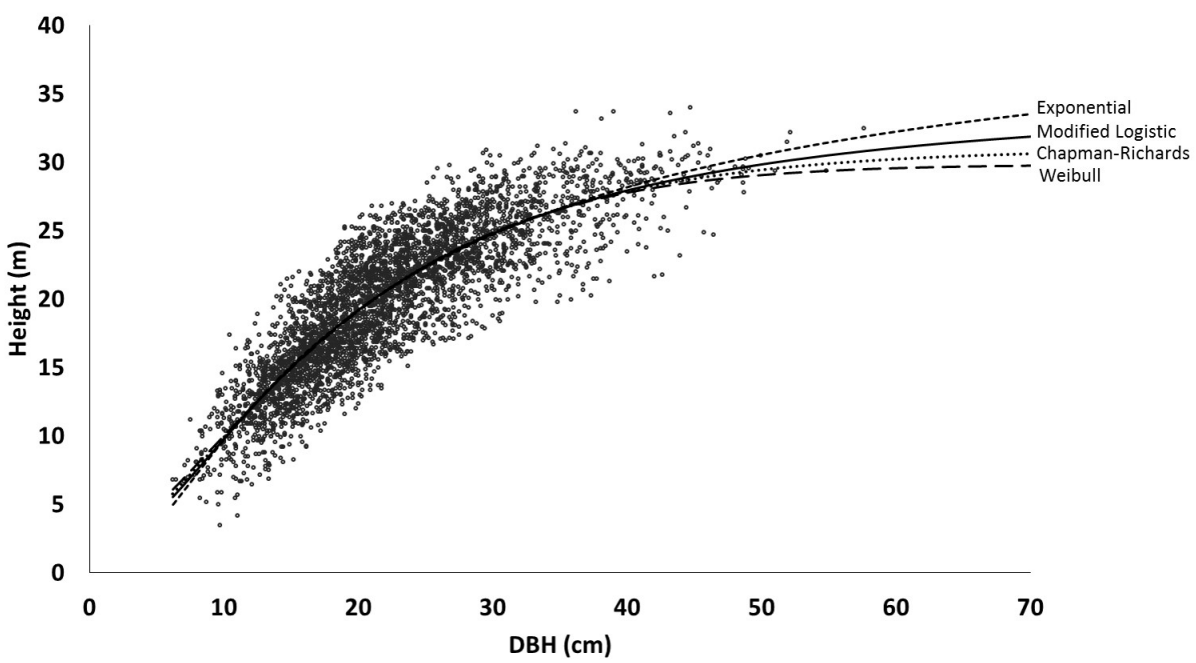

Fig. 2. Four different nonlinear model curves on scatter plot of height over DBH for Larix kaempferi. 
0.0089, MAD=2.0896 (Table 3).

Four different nonlinear height-DBH mode curves on scatter plot for Larix kaempferi were shown in Fig. 2. All model curves approached horizontal asymptotes. The plots of residuals over the predicted height from height-DBH models showed no systematic pattern. It obviously verified the presence of homoscedasticity, and thus the models fit the data (Fig. 3).

\section{Model comparison}

The model curves of this study were compared with those of previous studies; Lumbres et al. (2011) and Seo et al. (2011). The shapes of the model curves were different among three studies (Fig. 4).

The curves in our study were noticeably above those in the other studies, while the curves by Seo et al. (2011) were below those by Lumbres et al. (2011). The principal reason caused such a different pattern could be attributed to the difference of the study regions. The models from the two previous studies were analyzed with the data of
Chungcheong region for Seo et al. (2011) and full data set of National Forest Inventory in 2007 and 2008 for Lumbres et al. (2011). Thus, our model curves with higher asymptotic parameters showed that Gangwon and North Gyeongsang province have better height growth for Larix kaempferi than other regions.

\section{Conclusion}

This study was carried out to estimate the best-fit the height-DBH growth model for Larix kaempferi in Gangwon and North Gyeongsang province. Four widely used nonlinear models, Exponential, Modified Logistic, Chapman-Richards, and Weibull, were fitted to the inventory dataset of $\mathrm{DBH}$ and height. All functions were significant at the $5 \%$ level. In the process of all model validation, $\mathrm{R}^{2}$ for each model was $>0.0983$. RMSE ranged from 2.6204 to 2.6144, MD from 0.0001 to 0.0108 , and MAD from 2.0896 to 2.0975. Also, no abnormal trend was found in residual plots. Weibull model was verified as the
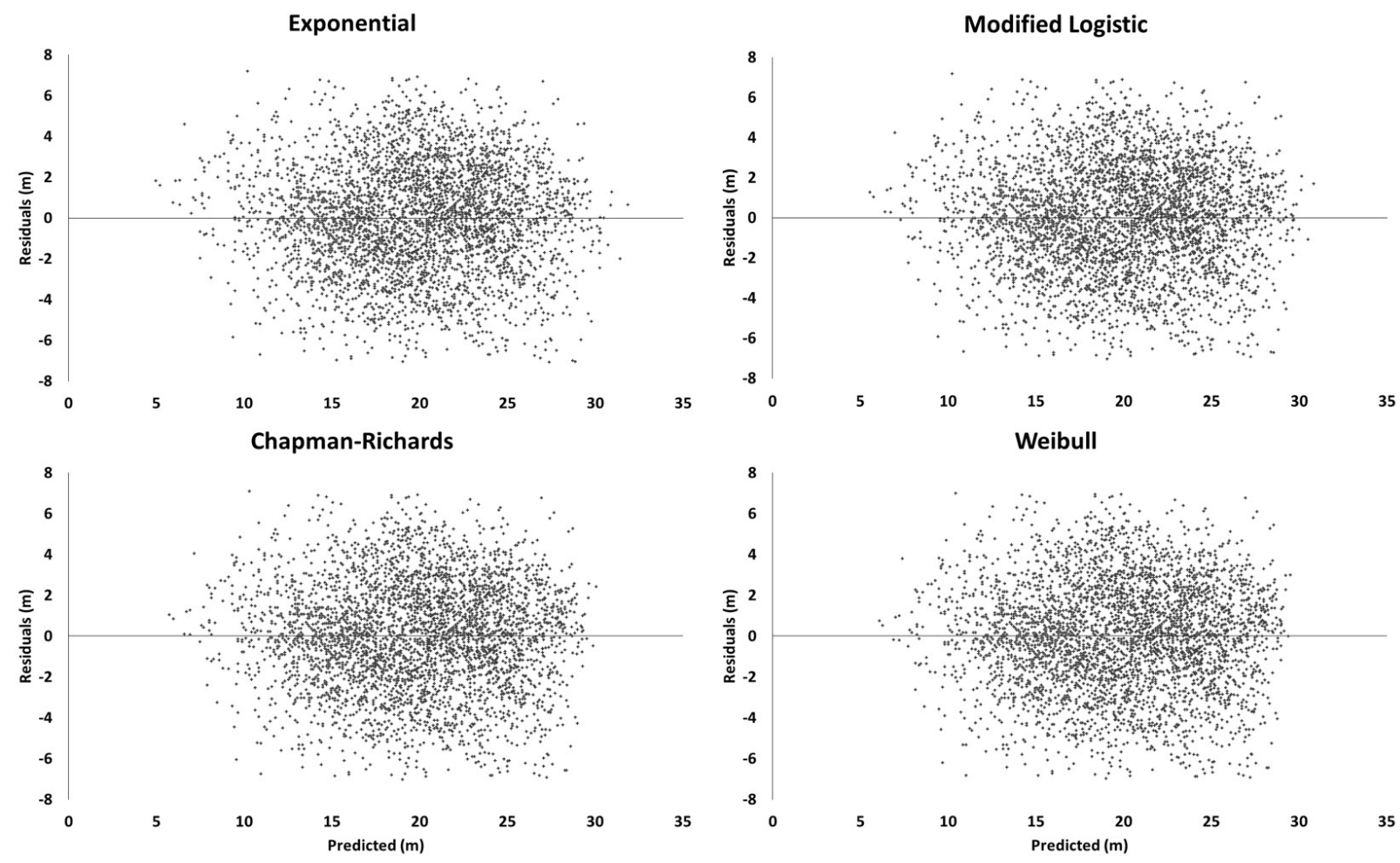

Fig. 3. The residual plots for the nonlinear height-DBH growth models of Larix kaempferi. 

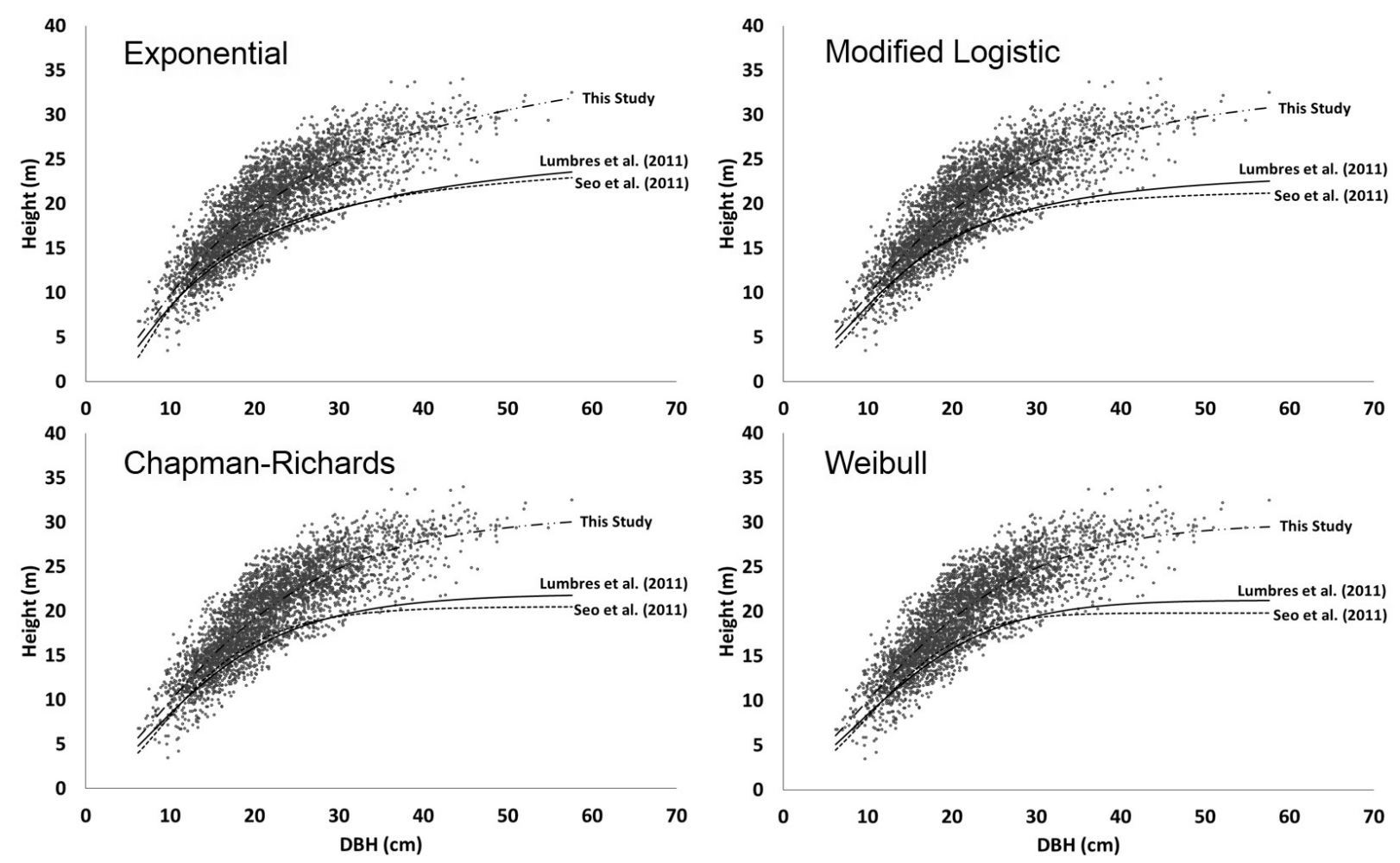

Fig. 4. The comparison of model curves between our study and the previous studies for Larix kaempferi.

best-fit model throughout all validation.

All the model curves presented the similar pattern particularly ranged from DBH $10 \mathrm{~cm}$ to $40 \mathrm{~cm}$. The asymptotes in all models were higher than those of the previous studies. This result suggests that the growth of tree height would be higher in Gangwon and North Gyeongsang province than in the other provinces.

Our models are highly expected to be used for estimating the tree height over DBH for Larix kaempferi, especially in Gangwon and North Gyeongsang province.

\section{Acknowledgements}

This study was carried out with the support of 'Long-term Monitoring Research for Major Species on Climate Change' funded by Northern, Eastern, and Southern Regional Office of Korea Forest Service in 2013 and the support of 'The model development for management scale improvement of private forests in Korea' funded by Korea Forest Service in 2013.

\section{References}

Avery TE, Burkhart HE. 2002. Forest Measurements. 5th ed. McGraw-Hill, New York, NY, pp 456.

Chapman DG. 1961. Statistical problems in dynamics of exploited fisheries populations. Proceedings of the 4th Berkeley Symposium on Mathematical Statistics and Probability. Vol. 4. Berkeley, CA. pp 153-168.

Dorado FC, Diéguez-Arandab U, Anta MB, Rodríguez MS, von Gadowc K. 2006. A generalized height-diameter model including random components for radiata pine plantations in northwestern Spain. For Ecol Manage 229: 202-213.

Hökkä H. 1997. Height-diameter curves with random intercepts and slopes for trees growing on drained peatlands. For Ecol Manage 97: 63-72.

Huang S, Titus SJ, Wiens DP. 1992. Comparison of nonlinear height-diameter functions for major Alberta tree species. Can J For Res 22: 1297-1304.

Kwak DA, Lee WK, Kim SW, Seo JH. 2004. Regional differences in height and taper form of Pinus densiflora in Korea. Kor J For Meas 7: 49-60. (in Korean with English abstract)

Korea Forest Service. 2012. Statistical Yearbook of Forestry. Korea Forest Service, Daejeon, pp 488. (in Korean) 
Korea Forest Research Institute. 2012. Commercial Tree Species 4 Larix kaempferi. Korea Forest Research Institute, Seoul, pp 168. (in Korean)

Lee DS, Choi JK. 2014. A study on stand structure and growth characteristics of Korean white pine (Pimus koraiensis) in north central region of Gangwon province. J For Sci 30: 101-106.

Lee WK. 1996. Stand and general height-DBH curve models for Pimus densiflora in Kangwon province. Kor J For Eco 4: 66-78. (in Korean with English abstract)

Lee YJ, Coble DW, Pyo JK, Kim SH, Lee WK, Choi JK. 2008. A Mixed-effects height-diameter model for Pius densiflora trees in Gangwon province, Korea. J Korean For Soc 98: 178-182.

Lumbres RIC, Lee YJ, Seo YO, Kim SH, Choi JK, Lee WK. 2011. Development and validation of nonlinear height-DBH models for major coniferous tree species in Korea. For Sci Tech 7: 117-125.

Ratkowsky DA, Reedy TJ. 1986. Choosing near-linear parameters in the four-parameter logistic model for radioligand and related assays. Biometrics 42: 575-582.
Ratkowsky DA. 1990. Handbook of Nonlinear Regression Models. Marcel Dekker Inc., New York, NY, pp 264.

Richards FJ. 1959. A flexible growth function for empirical use. J Exp Bot 10: 290-301.

SAS Institute Inc. 2011. SAS/STAT 9.3 User's Guide. SAS Institute Inc., Cary, NC.

Sánchez-González M, Cañellas I, Montero G. 2007. Generalized height-diameter and crown diameter prediction models for cork oak forests in Spain. Invest Agrar-Sist R 16: 76-88.

Seo YO, Lee YJ, Rho DK, Kim SH, Choi JK, Lee WK. 2011. Height-DBH growth models of major tree species in Chungcheong province. J Korean For Soc 100: 62-69. (in Korean with English abstract)

Soares P, Tomé M. 2002. Height-diameter equation for first rotation eucalypt plantations in Portugal. For Ecol Manage 166: 99-109.

Yang RC, Kozak A, Smith JHG. 1978. The potential of Weibulltype functions as flexible growth curves. Can J For Res 8: 424-431. 